Please do not remove this page

RMIT

UNIVERSITY

\title{
Water redistribution determines photosynthetic responses to warming and drying in two polar
} mosses

Stanton, Daniel; Merlin, Morgane; Bryant, Gary; Ball, Marilyn

https://researchrepository.rmit.edu.au/esploro/outputs/9921859458301341/filesAndLinks?institution=61RMIT_INST\&index=null

Stanton, D., Merlin, M., Bryant, G., \& Ball, M. (2014). Water redistribution determines photosynthetic responses to warming and drying in two polar mosses. Functional Plant Biology, 41(2), 178-186.

https://doi.org/10.1071/FP13160

Document Version: Accepted Manuscript

Published Version: https://doi.org/10.1071/FP13160

Repository homepage: https://researchrepository.rmit.edu.au

(C) CSIRO 2014

Downloaded On 2023/04/27 00:45:40 +1000

Please do not remove this page 
Thank you for downloading this document from the RMIT Research Repository.

The RMIT Research Repository is an open access database showcasing the research outputs of RMIT University researchers.

RMIT Research Repository: http://researchbank.rmit.edu.au/

\section{Citation:}

Stanton, D, Merlin, M, Bryant, G and Ball, M 2014, 'Water redistribution determines photosynthetic responses to warming and drying in two polar mosses', Functional Plant Biology, vol. 41, no. 2, pp. 178-186.

See this record in the RMIT Research Repository at:

http://researchbank.rmit.edu.au/view/rmit:23279

Version: Accepted Manuscript

Copyright Statement: (C) CSIRO 2014

Link to Published Version:

http://dx.doi.org/10.1071/FP13160 


\title{
Water redistribution determines photosynthetic responses to warming and drying in two polar mosses
}

\author{
Daniel E. Stanton* ${ }^{1}$, Morgane Merlin ${ }^{1,2}$, Gary Bryant ${ }^{3}$, Marilyn C. Ball ${ }^{1}$ \\ ${ }^{1}$ Plant Science Division, Research School of Biology, The Australian National University, Canberra ACT 0200, \\ Australia \\ ${ }^{2}$ École Normale Supérieure, Paris, France \\ ${ }^{3}$ School of Applied Sciences, RMIT, Melbourne VIC 3001, Australia \\ *Author for correspondence: daniel.stanton@anu.edu.au
}




\title{
Summary:
}

To understand and predict the effects of climate change on organisms requires the disentangling of the effects of temperature and humidity (which can change with temperature). By carefully controlling air moisture as well as temperature we show that Antarctic mosses are not affected by a wide range of temperatures but instead respond strongly to humidity. This finding is crucial to making accurate prediction of how polar vegetation (in which mosses often dominate) will respond to current and future climate changes.

\begin{abstract}
:
Predicting impacts of climate change requires an understanding of the sensitivity of species to temperature, including conflated changes in humidity. Physiological responses to temperature and clump-to-air vapour pressure difference (VPD) were compared in two Antarctic moss species, Ceratodon purpureus and Schistidium antarctici. Temperatures from 8 to $24^{\circ} \mathrm{C}$ had no significant effects on photosynthesis or recovery from drying, while high VPD accelerated drying. In Schistidium, which lacks internal conduction structures, shoots dried more slowly than the clump, and photosynthesis ceased at high shoot relative water content (RWC), behavior consistent with a strategy of drought avoidance although desiccation tolerant. In contrast, shoots of Ceratodon have a central vascular core, but dried more rapidly than the clump. These results imply that cavitation of the hydroid strand enables hydraulic isolation of extremities during rapid drying, effectively slowing water loss from the clump. Ceratodon maintained photosynthetic activity during drying to lower shoot RWC than Shistidium, consistent with a strategy of drought tolerance. These ecophysiological characteristics provide a functional explanation for the differential distribution of Shistidium and Ceratodon along moisture gradients in Antarctica. Thus, predicting responses of non-vascular vegetation to climate change at high latitudes requires greater focus on VPD and hydraulics than temperature.
\end{abstract}

Keywords: Antarctic bryophytes, Ceratodon, Schistidium, climate change, hydraulics, VPD, temperature response. 


\section{Introduction}

Global changes in temperature and precipitation have the potential to greatly modify composition and distribution of plant communities, with alpine and polar ecosystems thought to be particularly sensitive due to constraints of cold adaptation. Many high-latitude organisms are able to function at lower temperatures than their lower-latitude counterparts, and evidence of cold adaptation can be found in many taxa (e.g. Berry and Bjorkman 1980). Although cold adaptation can involve a downward shift in temperature optima, it may also simply reflect a broadening of the temperature response curve. Many organisms in such extreme environments inhabit microhabitats that may be significantly warmer than their surroundings and may therefore require tolerance of warm conditions. For example, small plants in direct sunlight can easily reach temperatures of $10^{\circ} \mathrm{C}$ above their surroundings (e.g. Warren Wilson 1957; Longton 2008).

A particular challenge to the prediction of physiological responses to climate is that the effects of temperature and water stress are easily conflated. Temperature changes may not only affect biochemical processes, but also influence evaporative demand by changing water vapor pressure. In vascular plants stomatal control of water loss may buffer some of this indirect effect of temperature; however, the resulting reduction in carbon fixation may still be significant. Furthermore, much of the vegetation at high latitudes is non-vascular and poikilohydric. Poikilohydric organisms, such as many bryophytes, are assumed to exert limited control over their internal water status in response to external conditions (notably due to the absence of stomata in the gametophytic stage), although the wealth and extent of regulatory mechanisms employed is often under-appreciated (Proctor and Tuba 2002). Within groups such as mosses a wide array of morphological and anatomical structures influence water transport and retention, which can be both internal and external to the individual shoots (Hébant 1977).

The physiological responses of plants are often studied at a fixed state of hydration. However, poikilohydric organisms, in particular those from high-latitude cold deserts, are repeatedly subject to wetting and drying cycles, and rarely experience extended periods of hydration outside of certain microhabitats (such as clear lake bottoms). The frequency of these cycles can be an important determinant of species distributions (Wasley et al. 2006). A dynamic understanding of plant responses to temperature and evaporative demand during drying is therefore likely to be more relevant to the prediction of responses to climate change than considerations of steady-state activity at constant hydration (Coe, Belnap and Sparks 2012). In a moss clump, drying occurs primarily in the upper photosynthetic region of the shoots whereas water storage occurs primarily in a spongy core. Redistribution of water from the core to shoots can follow a number of pathways according to the species and even ecotype of moss. Although proto vascular systems analogous to the phanerogam xylem are found in a number of taxa (e.g. Tansley and Chick 1901, Hébant 1977, Ligrone et al. 2000), considerable internal water movement can also occur via other symplastic or apoplastic pathways.

We examined the responses to temperature and evaporative demand (as determined by clump-to-air vapor pressure difference) of two co-occurring Antarctic moss species of differing distribution and morphology. Ceratodon purpureus (Hedw.) Brid. is a cosmopolitan species found in a wide range of habitats from the poles to urban sidewalks. The stems of C. purpureus contain hydroids (Lenné et al. 2010), specialized cells analogous to the xylem of vascular plants (Hébant 1977). Schistidium antarctici (Cardot) L.I. Savicz and Smirnova is an Antarctic endemic with a "small and indistinct" central strand (Ochyra, Lewis-Smith and Bednarek-Ochyra 2008). Both species form short carpets (turves) of very densely packed shoots that constitute the most extensive form of vegetation in some parts of continental Antarctica (e.g. Selkirk and 
Seppelt 1987, Okitsu et al 2004)

We hypothesized that: (1) the cosmopolitan species (C. purpureus) would be less sensitive to temperature than the Antarctic endemic (S. antarctici) due to its much wider geographic distribution; however (2) clump-to-air vapor pressure difference (VPD) would have a greater impact on photosynthetic activity than temperature alone, and (3) high VPD would more negatively impact the species lacking specialized hydraulic structures (S. antarctici) by dehydrating shoots faster than they can be replenished.

\section{Materials and Methods:}

Samples from the two species Schistidium antarctici (Cardot) L.I. Savicz and Smirnova and Ceratodon purpureus

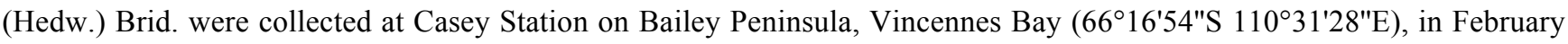
2012 at the end of the summer season. Schistidium antarctici grows in melt ponds and streams while C. purpureus is commonly found in dry locations at this station. Due to strict sampling regulations on very slow growing species from continental Antarctica, only $10 \mathrm{~cm}^{2}$ of each species could be collected. Such a sample could contain numerous genetic individuals and represents a level of organization intermediate between an individual and a population (for a discussion of structural correspondences between mosses and vascular plants, see Waite and Sack 2010). On arrival at the Australian National University, Canberra, Australia, the moss turves were sprayed with fungicide and the two species placed in separate sealable plastic containers to maintain high humidity, and then stored in a Controlled Environment Facility at $6^{\circ} \mathrm{C}$ under light at $200 \mu \mathrm{mol} \mathrm{m} \mathrm{m}^{-2} \mathrm{~s}^{-1}$. Mosses were maintained in a dehydrated state to inhibit growth of new shoots potentially adapted to growth chamber rather than field conditions.

Moss samples were placed in bays within a purpose-built, temperature-controlled brass chamber with a window enabling measurement of chlorophyll fluorescence under defined conditions of light, temperature, and gas composition. Temperature within the chamber was maintained by cooling fluid pumped through conduits in the walls of the chamber by a computer controlled, external circulating water bath (Julabo F32 HL, Germany), referenced against a platinum resistance thermometer. The moss chamber was connected in series between a portable photosynthesis system (LiCOR Li6400XT, LiCOR, USA) and a leaf chamber (LiCOR Li6400XT, LiCOR, USA) for control of gas flow. A plexiglass window in the chamber lid permitted illumination from above by a bank of computer-controlled LEDs providing both actinic light and the beams for measurement of chlorophyll fluorescence with an Imaging-PAM Chlorophyll Fluorometer (Walz IMAG-K4, Walz, Germany). The photosynthetic light $\left(179 \mu \mathrm{mol} \mathrm{m}^{-2} \mathrm{~s}^{-1}\right)$ incident on moss surfaces and measurement beam levels were previously determined sufficient to saturate photosynthesis without risk of signal oversaturation ( $\mathrm{Ft}<=0.200$ ).

Air was mixed in three steps to produce the concentrations of $\mathrm{CO}_{2}$ and water vapor required to generate the desired VPD treatment levels within the moss chamber. First, air in the incubator flowed through a $\mathrm{CO}_{2}$ scrubber to set $\mathrm{CO}_{2}$ levels approximately to zero. Second, air was saturated with water at a given temperature in a dew point generator (Li-COR Li610, LiCOR, USA) to achieve the desired VPD value in the chamber. Finally, $\mathrm{CO}_{2}$ was added at a concentration of $400 \mathrm{ppm}$. Since changes in temperature along the gas line can lead to condensation, the entire apparatus was placed within a large incubator (Thermoline scientific TRIL-1175-SD-15L, Australia) and controlled externally. Conditions within the air space of the moss chamber were monitored and recorded externally using a thermocouple (K-type) and humidity probe (HIH4021, Honeywell, USA) attached to a Datataker 500 datalogger (Thermo Fisher Scientific Australia, Australia). 
Paired samples of both study species were subjected to a drying and rehydration cycle under various combinations of ecologically relevant temperatures and vapour pressures. Three temperatures were chosen that are consistent with naturally occurring summer temperatures in Antarctic moss turves at Casey Station (Bölter 1992). Three VPD levels were selected to drive differences in evaporation rates but also enable comparisons to be made of the effects of temperature on responses to different evaporation rates: $0.2 \mathrm{kPa}\left(\right.$ at $8^{\circ} \mathrm{C}$ and $16^{\circ} \mathrm{C}$ ), $0.5 \mathrm{kPa}\left(\right.$ at $8^{\circ} \mathrm{C}, 16^{\circ} \mathrm{C}$ and $24^{\circ} \mathrm{C}$ ) and $1.2 \mathrm{kPa}\left(\right.$ at $16^{\circ} \mathrm{C}$ and $24^{\circ} \mathrm{C}$ ). At least three replicates were measured for each temperature-VPD pairing. All samples were used no more than once to avoid pseudoreplication and simultaneously run samples were treated as pseudoreplicates (the chamber contained 4 bays, allowing 2 samples of each species to be processed at a time). The paired design prevented the direct measurement of photosynthesis by gas exchange.

\section{Physiological responses to desiccation:}

We measured changes in relative water content (RWC), solute concentration, cellular dimensions and chlorophyll fluorescence during drying under different combinations of temperature and VPD. Subsamples $(1.5 \mathrm{~cm} \mathrm{x} 1 \mathrm{~cm})$ of each species were removed from the larger turves using a razor blade, retaining at least $5 \mathrm{~cm}$ of depth. They were thoroughly cleaned without disrupting the clump structure by gently agitation into three successive tap water baths. Removal of soil particles avoided biased measurement of dry mass and water holding capacity. Each sample was rehydrated in small petri dishes at $6^{\circ} \mathrm{C}$ for 12 hours under dim light $\left(\mathrm{PAR}=50 \mu \mathrm{mol} \mathrm{m}^{-2} \mathrm{~s}^{-1}\right.$ ) prior the start of the experiment. Samples were then blotted to remove excess external water, and the fresh weight was recorded. The samples weighed from $0.5 \mathrm{~g}$ to $1.5 \mathrm{~g}$. They were placed in small pre-weighed aluminum baskets in the moss chamber, which allowed the density of shoots found in an intact turf to be retained and any edge effects to be minimized. Care was taken to expose only the upper surface of the sample to air flow in the chamber. Moss samples were then allowed to desiccate in the moss chamber under fixed temperature and VPD conditions until chlorophyll fluorescence was completely quenched. Chlorophyll fluorescence (average of five representative points of high activity) and the weight of each clump were measured at 4 hour intervals (6 hour intervals for very slow drying conditions). At each time point Fv/Fm was measured following 20 minutes of dark acclimation, after which light was turned back on and saturating pulses applied at 5 minute intervals until Ft and Fm were stable.

At each time point, a few shoots from each canopy were sampled for water content, solute concentration and microscopic measurements of cell dimensions. These subsamples were taken from across the clump and were too small to create significant gaps in the canopy. At the end of drying (complete quenching of PSII fluorescence), mosses were weighed, then fully rehydrated and allowed to recover for approximately two hours under the designated temperature and VPD treatment with light at $179 \mu \mathrm{mol} \mathrm{m} \mathrm{m}^{-2} \mathrm{~s}^{-1}$, after which chlorophyll fluorescence was measured. Moss samples and subsamples for differential scanning calorimetry were then dried to constant dry weight in a $60^{\circ} \mathrm{C}$ oven for three days.

\section{Relative Water Content:}

Relative water content (RWC) of each sample was calculated using the data obtained by weighing the samples using a precision balance (Mettler AM100, Mettler Toledo, USA). The weight of sample and aluminum basket was measured prior to chlorophyll fluorescence measurement. The RWC (expressed in $\mathrm{g}$ of water per g of dry weight sample, see Slatyer 1967) was calculated for each measurement point. The fresh weight is the sample weight corrected for the 
aluminum basket weight and removed subsamples. The final dry weight is the weight of each sample after 72 hours drying at $60^{\circ} \mathrm{C}$ in an oven.

\section{Differential Scanning Calorimetry:}

Changes in solute concentration and osmotic potential during drying were measured with the DSC (Differential Scanning Calorimetry) method. Tzero hermetic lids (T11115, TA Instruments, USA) and low mass pans (T110920) for DSC analysis were pre-weighed using a high-precision balance (Mettler Toledo AX205, Mettler Toledo, USA ). A few shoot tips from each clump were placed in a pan, and hermetically sealed with a lid. The pan/lid/sample were weighed to obtain the sample fresh mass. The experimental runs with the differential scanning calorimeter (DSC600, Linkam, UK) started from $+20.0^{\circ} \mathrm{C}$ and then cooled down to $-40.0^{\circ} \mathrm{C}$ at $10^{\circ} \mathrm{C}$ per minute, then back to the start temperature. This was repeated three times to ensure consistency in the results. This ramp rate is not meant to be biologically relevant, but it is needed in order to accurately determine the temperature and enthalpy of freezing events. The Linksys32 software (Linkam, UK) was then used to determine the peak position, peak area and the phase transition onset temperature. When the DSC scans were completed, the DSC pans were pierced at the top and placed in the oven at $60^{\circ} \mathrm{C}$ for three days to obtain dry masses. Both solute concentration and water volume influence the melting temperature as measured by the DSC, and so to convert peak transition values to solute concentrations a serial dilution of sucrose solutions was prepared (0M, $0.25 \mathrm{M}, 0.5$ $\mathrm{M}, 1 \mathrm{M})$ and analysed using the same settings as employed for samples for a range of water volumes $(1 \mu \mathrm{L}, 2.5 \mu \mathrm{L}, 5 \mu \mathrm{L}$, $7.5 \mu \mathrm{L}, 10 \mu \mathrm{l}, 15 \mu \mathrm{L})$.

\section{Photosynthetic response:}

Photosynthetic efficiency for each sample at each time point and after the recovery time was determined using the photosynthetic yield $\mathrm{Fv} / \mathrm{Fm}$ (ratio of the variable fluorescence to the maximal fluorescence). $\mathrm{Fm}$ is the maximal fluorescence equivalent to that which would be attained in the absence of photochemical quenching and Fo the minimum fluorescence in the absence of actinic (photosynthetic) light (Maxwell 2000). Both were measured after a 30 minute dark adaptation using an Imaging PAM chlorophyll fluorometer and its head IMAG-K4 (H. Walz, Germany).

The dark-adapted Fv/Fm reflects the potential quantum efficiency of photosystem II (PSII). The Fv/Fm is commonly used as a sensitive indicator of environmental stress and plant photosynthetic performances (Maxwell 2000). It is used here to compare the photosynthesis response of the two species of mosses to the different treatments.

\section{Statistical analysis:}

The statistical analysis to compare the response of the different species, and the difference between temperature and VPD was made using the statistical program R (version 2.15.0 R Development Core Team, 2012).

For most of the replicates of treatment conditions only one sample of each species was used. Three runs were done using two clumps of $S$. antarctici and $C$. purpureus each time, and thus a new random discrete variable "pseudoreplicate" was added to the following models. It takes into account the fact that for these last runs the samples were paired.

The slopes of the drying rates were calculated by assuming drying rate to be a first order rate constant, and therefore equal to the slope of the log of RWC against time. The effects of temperature, VPD and species, and their interactions on drying rates, were assesed by ANOVA. The other parameters measured (shoot RWC, solute concentration, 
maximum Fv/Fm, and cell measurements) were evaluated against RWC to remove the impact of differences in drying rates with treatment. As they involved repeated measures in time, we used mixed effects linear models maximising log-likelihood in which temperature, VPD and species were fixed effects and run number, pseudoreplicate, and timepoint were random variables (function lme in $\mathrm{R}$ package nlme, Pinheiro et al. 2013). Logarithmic or square root transformations were performed when necessary to meet the criteria of homogeneity, normality and independence of the residuals. The same procedure was performed for changes in solute concentration with shoot RWC. We performed progressive simplification of fixed effects by ANOVA to obtain the minimal adequate model .

\section{Results}

\section{Drying Rates:}

Water loss, as measured by reduction in RWC, from moss clumps was exponential (e.g. Fig 1a) and expressed as a first order decay function. Drying rates were significantly influenced by VPD and species but not temperature (Table 1). There were no significant interactions between factors.

The clumps did not dry evenly, but instead shoots dried at different rates from the overall clump (Fig. 2a). The relative water contents of shoots and clumps had to be logarithmically transformed to meet assumptions of normality and linearity. The best fit LME model $(\log ($ clump RWC $)+$ Species, random effects $=$ Replicate, Pseudoreplicate, Timepoint) included no interaction terms. Temperature (d.f. $=15, \mathrm{~F}=0.03013, \mathrm{p}=0.8645$ ) and VPD (d.f. $=15, \mathrm{~F}=2.5626, \mathrm{p}=0.1290$ ) had no significant effects on the relationship between clump and shoot RWC. The log-log slopes (1.18) did not differ between species but the intercepts did (-0.0384 for Ceratodon, -0.8834 for Schistidium), such that Ceratodon shoot RWC exceeded that of clumps at high RWC (Fig. 2b, dashed line) whereas Schistidium shoots contained consistently less water than the overall clump (Fig. 2b, solid line).

A closer examination of the data for Ceratodon in Figure 2a suggests a biphasic interaction between shoot and clump RWC. We fitted a two segment piece-wise linear regression LME to the data for Ceratodon, retaining the same random effects as above. The break-point (clump RWC $=2.05 \mathrm{~g} \mathrm{~g}^{-1}$ ) was chosen by searching for the AIC minimum in the expected range of clump RWC values (1-3 $\left.\mathrm{g} \mathrm{g}^{-1}\right)$. Log-transformation was not required for either the piece-wise regression or the simple regression to meet assumptions of normality and heteroscedasticity. The piece-wise regression provided a better fit than simple linear regression by AIC comparison ( 446.3 for 8 d.f compared to 455.2 for 6 d.f., $p=0.0016$ ). Above the breakpoint there was no significant relationship between clump and shoot RWC (d.f. $=14, t=0.469, p<0.646$ ).

\section{Solute Concentration:}

As cells dry the solute concentrations increase in the cytoplasm. Solute concentration can be derived from freezing/melting temperature as measured by differential scanning calorimetry. Solute concentration was inversely related to shoot RWC, increasing to over 1.0 M by the end of the drying process (Fig. 3). The best fit LME for solute concentration showed significant interactions between shoot RWC and Species (d.f. $=88, F=8.128, p=0.0054$, Fig 3a) and between shoot RWC and Temperature (d.f. $=88, F=14.788, p=0.0002$, Fig $3 b$ ) with no significant effects of temperature or 
species alone. Although statistically significant, these interactions had such minute effects on concentration as to be highly unlikely to be biologically relevant (Fig. 3). Solute concentrations in both species increased sharply and linearly below an RWC of $\sim 1.5 \mathrm{~g} \mathrm{~g}^{-1}$.

\section{Photosynthetic dynamics during drying:}

The response of chlorophyll fluorescence to hydration state differed markedly between species (Fig 1b). In $S$. antarctici $\mathrm{Fv} / \mathrm{Fm}$ was nearly constant with declining clump RWC to a threshold between 2 and $3 \mathrm{~g} \mathrm{~g}^{-1}$, and Fv/Fm declined rapidly with further decrease in RWC. In C. purpureus Fv/Fm was depressed at high RWC, reached maximal values at intermediate RWC, and declined precipitously below an RWC of $1 \mathrm{~g} \mathrm{~g}^{-1}$. In both species basal chlorophyll fluorescence Fo declined steadily during the drying process. Mean maximal Fv/Fm was higher in S. antarctici than C. purpureus (0. 676 and 0.607 respectively, $\mathrm{P}<0.004)$, and occurred at a higher clump RWC $(\mathrm{P}<0.001)$.

Temperature and VPD had minor and inconsistent effects on maximal Fv/Fm. Although Fv/Fm was significantly lowered in C. purpureus at high VPD $(1.2 \mathrm{kPa})$, this was most likely due to failure of the sampling window to capture the full dynamics during very rapid drying, rather than any significant actual difference.

The clump RWC at the onset of photosynthetic decline did not change significantly with temperature $(\mathrm{p}>0.05)$ or VPD, but showed a strong trend towards earlier onset of decline at high VPD (Fig. 4A). The onset of decline occurred consistently at a significantly higher clump RWC in $S$. antarctici (median $=1.96 \mathrm{~g} \mathrm{~g}^{-1}$, standard deviation $=0.85$ ) than $C$. purpureus (median $=0.94 \mathrm{~g} \mathrm{~g}^{-1}$, standard deviation $=0.81 ; \mathrm{P}<0.001$ ) and the complete quenching of fluorescence also occurred at higher RWC in $S$. antarctici $\left(\mathrm{P}<1 \times 10^{-4}\right)$. The effect of VPD and any species differences were absent when the RWC of the photosynthetic shoots alone was considered (Fig. 4B), suggesting that the pattern was driven by differences between clump and shoot RWC.

\section{Recovery from drying:}

All individuals recovered within two hours of full rehydration $(89 \%$ of initial $\mathrm{Fv} / \mathrm{Fm}$, sd $=26 \%$, Fig $1 \mathrm{~b})$ with no significant differences between species $(\mathrm{P}<0.89)$. In C. purpureus recovery was greater at low VPD than at intermediate VPD $(\mathrm{P}<0.02)$, whereas $S$. antarctici showed no clear trends in recovery.

\section{Discussion}

The present study shows stability of the photosynthetic apparatus in the Antarctic mosses $S$. antarctici and $C$. purpureus, here assayed by measurement of dark-adapted $\mathrm{Fv} / \mathrm{Fm}$, over the temperature range from 8 to $24^{\circ} \mathrm{C}$. Quenching of Fv/Fm occurred in response to dehydration driven by temperature-dependent effects on VPD and species-dependent effects of morphology on shoot drying rates. This range of temperatures is consistent with the temperatures these mosses can experience during the summer season in Antarctica (e.g. Bolter 1992). When air temperature is above zero, the moss temperature can be much warmer, up to $15^{\circ} \mathrm{C}$ greater than air temperature (e.g. Warren Wilson, 1957). The effects of 
temperature and vapour pressure are easily confounded as the latter varies non-linearly with temperature and induces drying stresses, particularly in poikilohydric organisms such as mosses.

High latitude organisms are often thought to be cryophilic, showing a marked preference for cooler or cold temperatures. However, improved performance at low temperatures may not necessarily preclude resistance to warmer conditions, and is as likely to be the product of a widened, rather than shifted, temperature response curve. The absence of direct temperature effects in our study (Table 1) is consistent with other studies of Antarctic mosses (Davey and Rothery 1997, Pannewitz et al. 2005) which showed a broad range of temperatures at which photosynthesis in mosses is nearmaximal. In a study of benthic aquatic mosses which experience neither freezing nor drying stresses in Antarctic lakes, Kudoh, Kashina and Imura (2003) found that Leptobryum sp. and Bryum pseudotriquetrum tolerate a wide temperature range, only experiencing stress above $30^{\circ} \mathrm{C}$ or below $-20^{\circ} \mathrm{C}$.

Clump size and structure can also greatly influence drying rates (Zotz et al. 2000, Rice and Anderson 2001, Rice and Schneider 2004, Elumeeva et al. 2011). In our study clump size was artificially constrained by the bays of the sample chamber, so only differences in clump structure were able to influence the drying process. Wasley et al. (2006a) found that S. antarctici has a more loosely packed turf than C. purpureus, which could affect drying rate (Rice and Schneider 2004, Elumeeva et al. 2011). However, the greatest differences in drying observed in the present study appear to be driven by internal structure. Shoots dried at different rates than their clumps, with the pattern differing between species (Fig 2). In $S$. antarctici, the shoots dried more slowly than the clump (slope $<1$ ) while in C. purpureus the opposite occurred, with no VPD or temperature effect for either species. This suggests that the two species have different hydraulic dynamics during drying at the shoot level.

Differences in drying rates might be expected to be matched by different cellular responses to drying. The rapid cessation of activity, accompanied by rapid recovery, is a hallmark of desiccation tolerant plants, which differ from drought tolerant plants by spending very little time in partially dehydrated conditions (Proctor et al. 2007). Essential cell components are preserved through the desiccation process and metabolism cessation as well as metabolism restart are fully controlled (Proctor et al. 2007). At high RWC solute concentrations were largely unaffected by drying, but increased rapidly below a threshold of $\sim 1.5 \mathrm{~g} \mathrm{~g}^{-1}$ (Fig 3). Final solute concentration was unaffected by drying conditions or species, and seems likely to be constitutive rather than induced, similar to other bryophytes but unlike poikilohydric angiosperms (Oliver et al., 2005).

Photosynthetic activity, as measured by PSII efficiency, did vary with RWC. Many mosses show a hump-shaped response of photosynthesis to RWC, with depressed activity at both high and low RWC (Dilks and Proctor, 1978). Maximum PSII efficiency occurred at a significantly higher RWC for S. antarctici than for C. purpureus (median: 3.72 versus 1.66) and S. antarctici showed no depression of PSII activity at RWCs above 2. Reduced photosynthesis at high RWC is typically attributed to diffusion limitation through water films on the surface of saturated tissues. During drying, there were interspecific differences in the clump RWC at which decline in PSII efficiency (Fig 4a) occurred. Water stress occurred at higher clump RWC for $S$. antarctici than for C. purpureus, and the clump RWC at which the PSII efficiency reaches zero was also higher in $S$. antarctici than in C. purpureus (data not shown). Interestingly, these differences are absent at the shoot scale (Fig 4b), suggesting that these interspecific differences are again determined by hydraulic redistribution. 
In both moss species the decrease in PSII efficiency induced by drying was reversible. Chlorophyll fluorescence was measurable within minutes of rehydrating, as previously reported in these species (Davey and Rothery, 1997; Wasley et al. 2006a). The decrease was associated with a proportional decrease in Fo, a pattern consistent with photoprotective quenching. Photoprotection appears to be common in desiccation tolerant lichens and mosses, although its mechanisms are still under investigation (e.g. Heber et al. 2007, Yamakawa et al. 2012).

The differences in drying responses between $S$. antarctici and C. purpureus suggest alternative functional strategies. The high RWC tolerant $S$. antarctici recovers nearly immediately upon re-wetting, yet ceases photosynthesis at a relatively greater RWC, seemingly functioning best when very hydrated and poorly when partially hydrated (drought intolerance). Decline in activity is progressive as leaf cells lose turgidity. In contrast, C. purpureus continues photosynthetic activity for longer during drying, yet ceases abruptly when cell shrinkage begins. PSII efficiency is higher at an intermediate to low RWC. Ceratodon shoots therefore perform better as they dehydrate than when fully hydrated, a drought-tolerant carbon acquisition strategy optimized for repeated wetting-drying cycles.

The correspondence between anatomy and drying pattern strongly suggests a dual role for vascular structures. While the vascular system facilitates rapid water redistribution within a plant, such rapid water movement might not be ideal if water reserves were depleted. Stomatal closure guards against such events in tracheophytes; however, stomata are absent in moss gametophytes. Cavitation of the vascular system would provide an alternative mechanism for rapid cessation of water transport to shoots in response to drying. Constitutive desiccation tolerance of bryophyte shoots ensures that cutting off the water supply will not cause tissue damage or death. Plant hydraulics are often depicted using electrical circuit diagrams: in this interpretation vascular tissues may be fuses rather than simple wires. A similar mechanism might also account for the "feed-forward" behaviour reported in vascular plants (Franks et al. 1997), in which stomata appear to sense water loss rate independently of the water content of the leaf (i.e. reducing water loss before dehydration occurs).

The differences in hydraulics between the two species appear to correspond to their microtopographic preferences. Ceratodon purpureus is found most commonly on drier summits of turves, and globally in disturbed areas, consistent with tolerance of drying but not saturating conditions (Wasley et al. 2006). Schistidium antarctici, tolerant of saturating conditions (Wasley et al. 2006), is found in the wetter hollows at Casey Station (Selkirk and Seppelt, 1987), but also in dry exposed locations elsewhere in Antarctica (Ochyra et al. 2008). A similar distribution is exhibited by other Grimmiaceae, such as the Antarctic endemic Coscinodon lawianus (= Grimmia lawiana), generally found in dry habitats (Ochyra et al. 2008) but also dominant in turf hollows (Okitsu, Imura and Ayukawa 2004). Mosses have been observed to be sensitive to freezing damage when fully hydrated (Lovelock et al. 1995), and so such bimodal distributions may reflect a preference for saturation followed by rapid drying, which avoids freeze damage in exposed sites and contrastingly provides a competitive advantage in wet microhabitats where thermal buffering reduces vulnerability to frost injury. Due to restrictions on the sampling of these very slow growing organisms, we were only able to compare single co-occurring populations of the two species. However, future comparisons of different populations across Antarctica would be of considerable interest.

These morphological and physiological differences between $S$. antarctici and C. purpureus as well as their different response to VPD help clarify the future distributions of these mosses communities in continental Antarctica. Some studies have predicted that increased temperature and increased precipitation, two main predicted effects of climate change at the poles, would favor growth in bryophytes (Clarke et al. 2011, Robinson et al. 2003). However, concurrently increased wind speeds may increase evaporation rates. Current expansion of lichen covers suggests a tendency for a drier environment 
(Melick \& Seppelt, 1997). The far greater influence of VPD than temperature shown in the present study suggests that accurate modelling of future distributions of Antarctic plants is reliant on our ability to predict VPD and precipitation.

The rate and control of internal water redistribution in response to changes in evaporative demand appears to far outweigh direct temperature effects in influencing the physiological responses of Antarctic mosses. The differential degrees of dehydration (in contrast to drought) tolerance and dynamics match species distributions. We suggest that a focus on water relations and perhaps a hydraulic functional group classification for bryophytes are essential for development of models predicting responses of polar vegetation to climate warming.

\section{Acknowledgments:}

This research was funded by Australian Antarctic Science Program grants 2780 and 3061 and Australian Research Council Discovery grant DP110105380. The authors wish to thank Dr. T. Lenné for assistance with the DSC measurements, J. Egerton for help with sample collection and assistance with experimental set-up, Dr. M. Skotnicki for sample collection, Dr. Hwan-Jin Yoon of the ANU Statistical Consulting Unit for assistance with data analysis and two anonymous reviewers for helpful suggestions that greatly improved clarity of the text.

\section{References:}

Berry J. and Bjorkman O. (1980) Photosynthetic Response and Adaptation to Temperature in Higher Plants. Annual Review of Plant Physiology and Plant Molecular Biology 31, 491-543.

Bolter M. 1992. Environmental conditions and microbiological properties from soils and lichens from Antarctica (Casey Station, Wilkes Land). Polar Biology 11: 591-599.

Clarke LJ, Robinson SA, Hua Q, Ayre DJ, Fink D. 2011. Radiocarbon bomb spike reveals biological effects of Antarctic climate change. Global Change Biology 18: 301-310.

Coe K.K., Belnap J. and Sparks J.P. (2012) Precipitation-Driven Carbon Balance Controls Survivorship of Desert Biocrust Mosses. Ecology 93, 1626-1636.

Davey M.C. and Rothery P. (1997) Interspecific Variation in Respiratory and Photosynthetic Parameters in Antarctic Bryophytes. New Phytologist 137 (2): 231-240.

Dilks T.J.K. and Proctor M.C.F. (1979) Photosynthesis, Respiration and Water-Content in Bryophytes. New Phytologist 82 , $97-114$.

Elumeeva T.G., Soudzilovskaia N.A., During H.J. and Cornelissen J.H.C. (2011) The Importance of Colony Structure Versus Shoot Morphology for the Water Balance of 22 Subarctic Bryophyte Species. Journal of Vegetation Science 22, $152-164$

Franks P.J., Cowan I.R. and Farquhar G.D. (2008) The Apparent Feedforward Response of Stomata to Air Vapour Pressure Deficit: Information Revealed by Different Experimental Procedures with Two Rainforest Trees. Plant, Cell and Environment 20, 142-145.

Hébant C. (1977) The Conducting Tissues of Bryophytes. J. Cramer Verlag, Vaduz, Liechtenstein.

Kanda H., Imura S. and T. Ueno T. (2004) On the Structures of Moss Colony in the Yukidori Valley, Langhovde, East Antarctica. Polar Bioscience 17, 128-138. 
Kudoh S., Kashino Y. and Imura S.. (2003) Ecological Studies of Aquatic Moss Pillars in Antarctic Lakes 3. Light Response and Chilling and Heat Sensitivity of Photosynthesis. Polar Bioscience 16, 33-42.

Lenné T., Bryant G., Hocart C.H., Huang C.X. and Ball M.C. (2010) Freeze Avoidance: a Dehydrating Moss Gathers No Ice. Plant, Cell and Environment 33, 1731-1741.

Ligrone R., Duckett J.G., Renzaglia K.S. (2000) Conducting tissues and phyletic relationships of bryophytes. Philosophical Transactions Of The Royal Society B-Biological Sciences 355: 795-813.

Longton R.E. (1988) The biology of polar bryophytes and lichens. Cambridge University Press, Cambridge, UK.

Lovelock CE, Osmond CB, Seppelt RD. 1995. Photoinhibition in the Antarctic moss Grimmia antarctici Card when exposed to cycles of freezing and thawing. Plant, Cell and Environment 18: 1395-1402.

Melick D, Seppelt R. 1997. Vegetation patterns in relation to climatic and endogenous changes in Wilkes Land, continental Antarctica. Journal of Ecology 85: 43-56.

Ochyra R., Lewis Smith R.I. and Bednarek-Ochyra H. (2008) The Illustrated Moss Flora of Antarctica. Cambridge University Press, Cambridge, UK.

Okitsu S, Imura S. and Ayukawa E. (2004) Micro-Relief Distribution of Major Mosses in Ice-Free Areas Along the Soya Coast, the Syowa Station Area, East Antarctica. Polar Bioscience 17, 69-82.

Oliver M.J., Velten J., and Mishler B.D. (2005) Desiccation Tolerance in Bryophytes: a Reflection of the Primitive Strategy for Plant Survival in Dehydrating Habitats? Integrative and Comparative Biology 45,788-799.

Pannewitz S., Green T.G.A., Maysek K., Schlensog M., Seppelt R., Sancho L.G., Türk R. and Schroeter B.. (2005) Photosynthetic Responses of Three Common Mosses From Continental Antarctica. Antarctic Science 17, 341-352.

Pinheiro J., Bates D., DebRoy S., Sarkar D. and R Core Team. (2013) nlme: Linear and Nonlinear Mixed Effects Models. R package version 3.1-108.

Proctor M.C.F. (2000) The Bryophyte Paradox: Tolerance of Desiccation, Evasion of Drought. Plant Ecology 151, 41-49.

Proctor M.C.F., Oliver M.J., Wood A.J., Alpert P., Stark L.R., Cleavitt N.L. and BD Mishler B.D. (2007) DesiccationTolerance in Bryophytes: a Review. The Bryologist 110, 595-621.

Proctor M.C.F. and Tuba Z. (2002) Poikilohydry and Homoihydry: Antithesis or Spectrum of Possibilities? New Phytologist $156,327-349$.

R Core Team. (2012) R: A Language and Environment for Statistical Computing. R Foundation for Statistical Computing, Vienna, Austria. URL http://www.R-project.org/.

Rice S.K. and Schneider N. (2004) Cushion Size, Surface Roughness, and the Control of Water Balance and Carbon Flux in the Cushion Moss Leucobryum Glaucum (Leucobryaceae). American Journal of Botany 91, 1164-1172.

Rice S.K., Collins D. and Anderson A.M. (2001) Functional Significance of Variation in Bryophyte Canopy Structure. American Journal of Botany 88, 1568-1576.

Robinson S.A., Wasley J., Popp M. and Lovelock C.E. (2000) Desiccation Tolerance of Three Moss Species From Continental Antarctica. Functional Plant Biology 27, 379-388.

Selkirk P.M. and Seppelt R.D. (1987) Species distribution within a moss bed in Greater Antarctica. Symposia Biologica Hungarica 35, 279-284.

Seppelt R.D. (2004) The Moss Flora of Macquarie Island. Australian Antarctic Division, Kingston, Australia . 
Slatyer R.O. (1967) Plant-Water Relationships. Academic Press, London, UK.

Tansley AG, Chick E. 1901. Notes on the conducting tissue-system in Bryophyta. Annals Of Botany 15: 1-38.

Wasley J., Robinson S.A., Lovelock C.E. and Popp M. (2006). Some Like It Wet — Biological Characteristics

Underpinning Tolerance of Extreme Water Stress Events in Antarctic Bryophytes. Functional Plant Biology 33, 443455.

Waite M. and Sack L. (2010) How Does Moss Photosynthesis Relate to Leaf and Canopy Structure? Trait Relationships for 10 Hawaiian Species of Contrasting Light Habitats. New Phytologist 185, 156-172.

Wilson J.W. (1957) Observations on the Temperatures of Arctic Plants and Their Environment. Journal of Ecology 45, 499-531.

Zotz G., Schweikert A., Jetz W. and Westerman H. (2000) Water Relations and Carbon Gain Are Closely Related to Cushion Size in the Moss Grimmia pulvinata. New Phytologist 148, 59-67. 
Table 1: Summary of factors affecting of drying rates of Antarctic moss clumps. VPD-Clump to air vapour pressure difference; Df-Degrees of freedom; SS-Sum of Squares

\begin{tabular}{|l|l|l|l|l|}
\hline & Df & SS & F & P \\
\hline VPD & 1 & 0.010074 & 40.361 & $\mathbf{5 . 0 3 \times 1 0 - 6}$ \\
\hline Temperature & 1 & 0 & 0.528 & 0.4725 \\
\hline Species & 1 & 0.01309 & 6.074 & $\mathbf{0 . 0 1 8 9}$ \\
\hline VPD x Temperature & 1 & 0.00004 & 0.016 & 0.8993 \\
\hline VPD x Species & 1 & 0.00753 & 3.492 & 0.0703 \\
\hline Temperature x Species & 1 & 0.00145 & 0.674 & 0.4175 \\
\hline VPD x Temperature x Species & 1 & 0.00358 & 1.659 & 0.2065 \\
\hline
\end{tabular}


Figure 1: Representative results showing time dependent change in clump relative water content (a) and PSII efficiency (b) over the course of a drying period $\left(0.2 \mathrm{kPa}, 16^{\circ} \mathrm{C}\right)$ for Ceratodon purpureus (open circles, dashed line) and Schistidium antarctici (closed circles, solid line). The arrow indicates rehydration of the clumps after complete cessation of photosynthetic activity. 


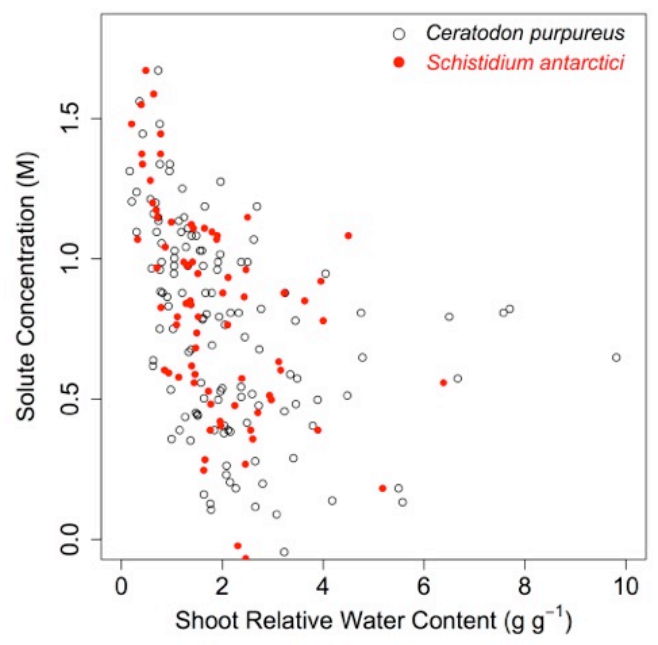

Figure 2: Relationship between clump and shoot relative water content (RWC, g of water/g dry mass) for C. purpureus (empty circles, dashed line) and S. antarctici (filled circles, solid line). Untransformed data is shown in panel a, with the dashed line showing the break point at which shoot and clump RWCs become decoupled (see results). Log-transformed data is shown in panel (b), the lines show fitted values for each species as determined by the best fit linear mixed effects (LME) model, with Species and RWC as fixed effects, and Replicate, Pseudoreplicate and Timepoint as random effects. 

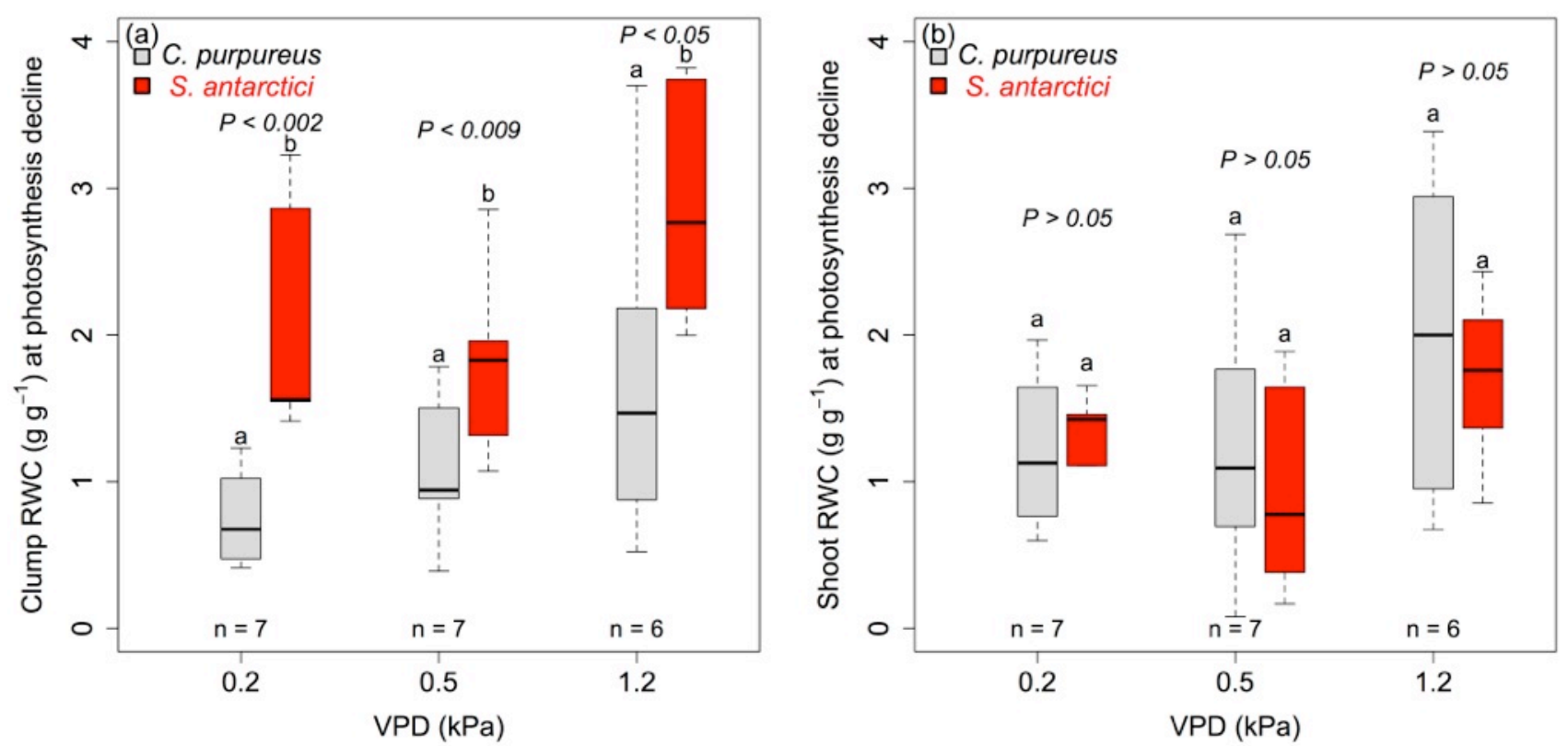

Figure 3: Relationship between cellular solute concentration (inferred from melting tempreature $T_{m}$ ) and relative water content of photsynthetic shoots (g of water / g of shoot dry mass), as separated by species (a Ceratodon purpureus-empty circles and Schistidium antarctici-filled circles) or temperature (b: $8^{\circ} \mathrm{C}$-open circles, $16^{\circ} \mathrm{C}$-stars and $24^{\circ} \mathrm{C}$-filled circles). Species and temperature were found to interact significantly with shoot relative water content as fixed effects in the best fit LME model for solute concentration, specifying Replicate, Pseudoreplicate and Timepoint as random effects. Although statistically significant, species and temperature effects are highly unlikely to be of biological importance. 

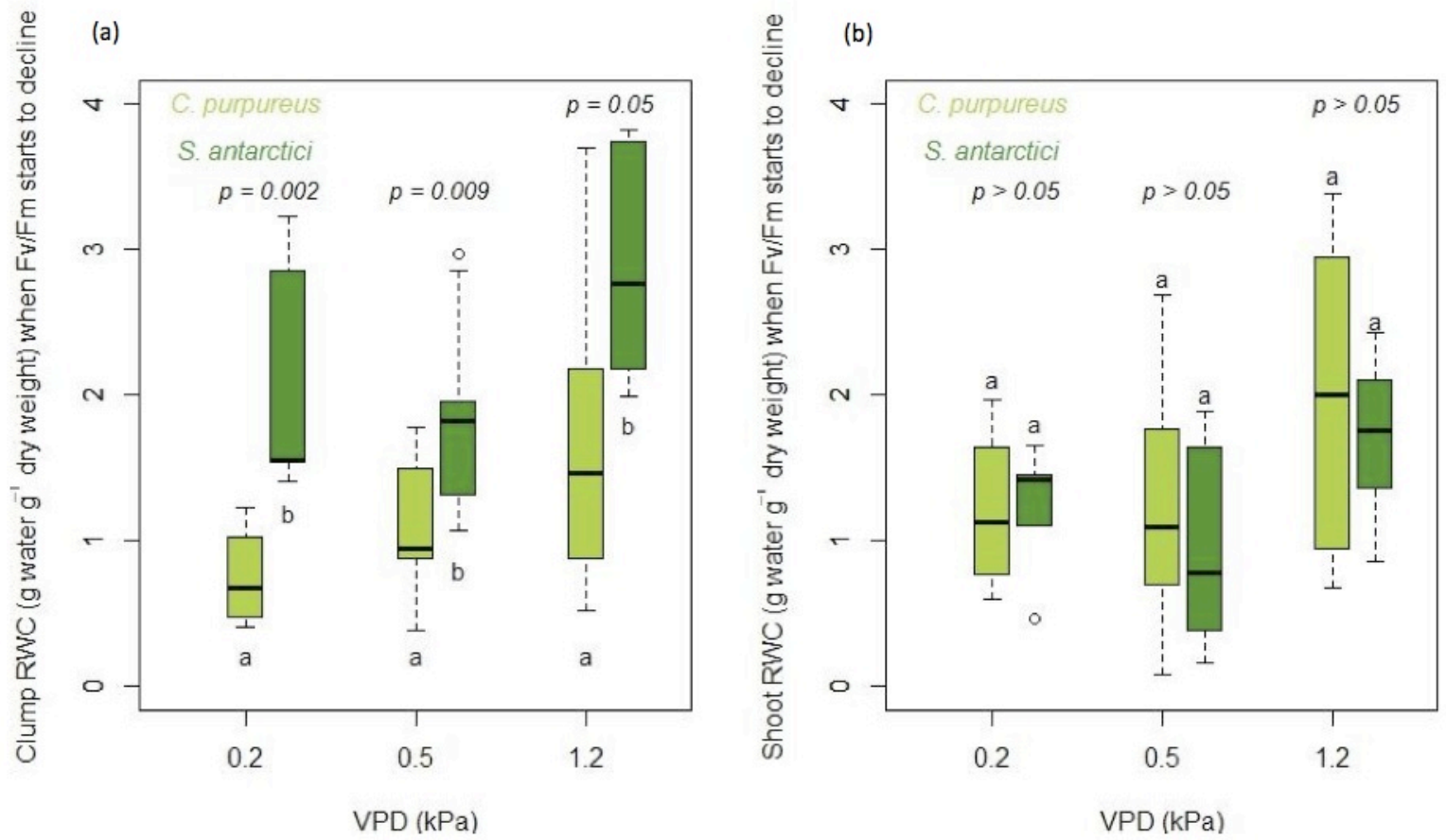

Figure 4: Relative water content of clumps (a) and photosynthetic shoots (b) at the onset of rapid decline in Fv/Fm during drying at different clump to air vapour pressure differentials (VPD). Bars with similar letters indicate that the treatments do not differ significantly when adjusted for multiple comparisons $(\mathrm{P}<0.05$, Tukey HSD test). $\mathrm{P}$ values are reported for the comparison between species at each VPD using ANOVA. 